\title{
Chromobacterium haemolyticum-induced bacteremia in a healthy young man
}

\author{
Megumi Okada ${ }^{1}$, Ryota Inokuchi ${ }^{1,2}$, Kazuaki Shinohara', Akinori Matsumoto', Yuko Ono ${ }^{1,3}$, Masashi Narita ${ }^{4}$, \\ Tokiya Ishida ${ }^{1}$, Chiba Kazuki ${ }^{5}$, Susumu Nakajima ${ }^{2}$ and Naoki Yahagi ${ }^{2}$
}

\begin{abstract}
Background: The genus Chromobacterium consists of 7 recognized species. Among those, only C. violaceum, commonly found in the soil and water of tropical and subtropical regions, has been shown to cause human infection. Although human infection is rare, C. violaceum can cause life-threatening sepsis, with metastatic abscesses, most frequently infecting those who are young and healthy.
\end{abstract}

Case presentation: We recently identified a case of severe bacteremia caused by Chromobacterium haemolyticum infection in a healthy young patient following trauma and exposure to river water, in Japan. The patient developed necrotizing fasciitis that was successfully treated with a fasciotomy and intravenous ciprofloxacin and gentamicin.

Conclusions: C. haemolyticum should be considered in the differential diagnosis of skin lesions that progressively worsen after trauma involving exposure to river or lake water, even in temperate regions. Second, early blood cultures for the isolation and identification of the causative organism were important for initiating proper antimicrobial therapy.

Keywords: Chromobacterium haemolyticum, Chromobacterium violaceum, Sepsis, Cellulitis, Necrotizing fasciitis

\section{Background}

The genus Chromobacterium consists of 7 recognized species: C. violaceum, C. subtsugae, C. aquaticum, C. haemolyticum, C. pseudoviolaceum, C. piscinae [1], and C. vaccinii [2]. Of these species, only C. violaceum, commonly found in the soil and water of tropical and subtropical regions, has been shown to cause human infection. Although human infection is rare, $C$. violaceum can cause life-threatening sepsis, with metastatic abscesses, most frequently infecting those who are young and healthy [3].

We describe, here, clinical evidence for another species, C. haemolyticum, which caused an infection in a healthy, young patient. This bacterium should be considered in the differential diagnosis of skin lesions that quickly worsen after trauma associated with exposure to river or lake water. This is particularly important because of the species' resistance to antimicrobials, particularly $\beta$-lactams.

\footnotetext{
* Correspondence: inokuchir-icu@h.u-tokyo.ac.jp

1 Department of Emergency and Critical Care Medicine, Ohta Nishinouchi Hospital, 2-5-20 Nishinouchi, 963-8558 Koriyama, Fukushima, Japan ${ }^{2}$ Department of Emergency and Critical Care Medicine, The University of Tokyo Hospital, 7-3-1 Hongo, 113-8655 Bunkyo-ku, Tokyo, Japan Full list of author information is available at the end of the article
}

\section{Case presentation}

A healthy, 26-year-old Japanese man was admitted to our hospital with pain in his left shoulder and leg caused by a road accident; he was hit by a car and thrown into a river. The outside air and water temperatures at the time of the injury were $20^{\circ} \mathrm{C}$. He had no family history of any particular condition.

Upon admission, his temperature was $36.6^{\circ} \mathrm{C}$; pulse rate, 66 beats/min; blood pressure, 143/99 $\mathrm{mmHg}$; respiratory rate, $15 / \mathrm{min}$; oxygen saturation, $100 \%$ (10-L reservoir mask); and Glasgow Coma Scale score, E4V5M6. A physical examination showed only bruising, not open wounds, on the left side of his face and shoulder and tenderness in his left leg. His height, weight, and body mass index were $175 \mathrm{~cm}, 67 \mathrm{~kg}$, and $21.9 \mathrm{~kg} / \mathrm{m}^{2}$, respectively. Laboratory tests showed mild inflammation (white blood cell [WBC] count, 13,500/ $\mu \mathrm{L}$; and C-reactive protein [CRP], $0.9 \mathrm{mg} / \mathrm{L}$ [normal range: $<2.0 \mathrm{mg} / \mathrm{L}$ ]). A radiograph showed fractures of the fibula shaft and scapula.

On post-admission day 3 , the patient exhibited a temperature of $40^{\circ} \mathrm{C}$, shivering, and redness and pain in his ankle. Intravenous ampicillin/sulbactam (6 g/day) 
and minocycline $(200 \mathrm{mg} /$ day $)$ were initiated. However, on the fourth day of admission, the antimicrobial drugs were changed to ceftazidime at $4 \mathrm{~g} /$ day, as 2 sets of blood culture tests revealed gram-negative bacilli. Until then, the redness in his ankle had not expanded. On day 5 , the erythematous, warmth and pain spread to his knee joint, and blisters were observed on the upper part of his foot (Figure 1). The patient was diagnosed with necrotizing fasciitis and a fasciotomy was conducted. The underlying muscle appeared healthy, and further debridement was avoided. The pathology of the dorsum of his left foot revealed inflamed skin and soft tissue, with necrosis consistent with necrotizing fasciitis. Laboratory tests showed an inflammatory reaction (WBC count, 13,500/ $\mu \mathrm{L}$; CRP, $196.3 \mathrm{mg} / \mathrm{L}$ ), and hyperglycemia (192 mg/dL). Thus, the Laboratory Risk Indicator for Necrotizing Fasciitis (LRINEC) score [4] was 6 (intermediate risk). The smear from the fasciotomy site and blood culture tests revealed gram-negative bacilli (Figure 2A), and the infecting bacterium was oxidase-positive and produced grey colonies, with a $4.3-\mathrm{mm}$ hemolytic zone on sheep blood-agar plates (Figure 2B); non-pigmented colonies were found on bromothymol-blue lactose agar plates, suggesting that $C$. haemolyticum was the causative

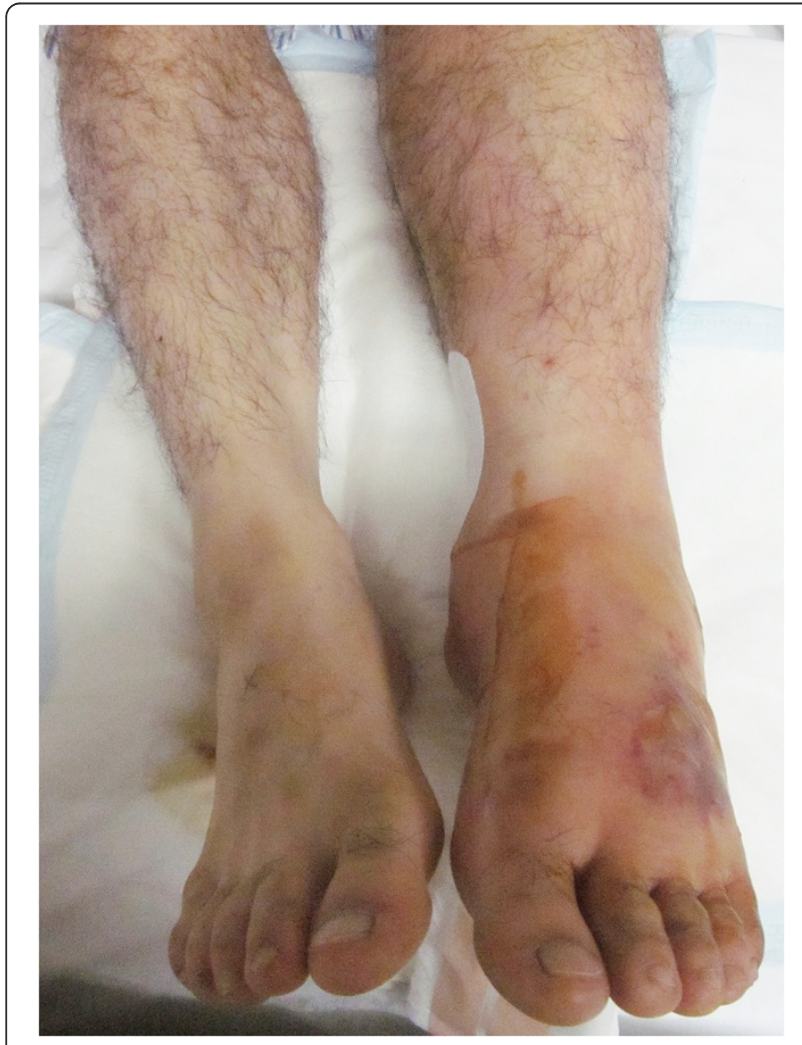

Figure 1 Clinical presentation on day 6.The patient experienced a burning sensation, tenderness, and redness in his left leg, from the upper part of his foot to his knee. Blisters are shown on the dorsum of the foot. agent. However, the Vitek GNI + card (bioMérieux Vitek, Hazelwood, MO, USA) and the API 20 NE test (bioMérieux Vitek) identified the organism as $C$. violaceum. The antibiotics were changed to intravenous ciprofloxacin $(900 \mathrm{mg} /$ day $)$ and gentamicin $(400 \mathrm{mg} /$ day $\left[6 \mathrm{mg} \cdot \mathrm{kg}^{-1} \cdot\right.$ day $\left.\left.^{-1}\right]\right)$. This antimicrobial regimen was continued for 28 days. After that, gentamicin was discontinued. The trough value of gentamicin was $0.3 \mu \mathrm{g} / \mathrm{mL}(6.1 \mu \mathrm{mol} / \mathrm{L})$ on days 8,10 , and 18 . On day 33 , the patient was discharged with a 14-day prescription for oral ciprofloxacin $\left(1600 \mathrm{mg} /\right.$ day $\left[25 \mathrm{mg} \cdot \mathrm{kg}^{-1} \cdot\right.$ day $\left.\left.^{-1}\right]\right)$. Therefore, this patient was treated with gentamicin for 23 days, intravenous ciprofloxacin for 28 days, and oral ciprofloxacin for 14 days. Subsequently, the identification of the C. haemolyticum strain, MDA0585 ${ }^{\mathrm{T}}$, was confirmed, based on its 16S rRNA gene sequence. Six months after the accident, the patient was free of recurrent infection.

\section{Discussion}

Before the recognition of C. haemolyticum in 2011, less than 140 proven cases of human infection with $C$. violaceum had been reported [3]. Among the few reports of infections caused by non-pigmented, $\beta$-hemolytic strains of C. violaceum, identification of $C$. haemolyticum strain $\mathrm{MDA} 0585^{\mathrm{T}}$ by $16 \mathrm{~S}$ rRNA gene sequencing has not been previously reported. Thus, we present the first clinical evidence for C. haemolyticum infection.

C. haemolyticum, strain MDA0585 $5^{\mathrm{T}}$, is a gram-negative bacillus, and has been isolated from a clinical sample [5] and from lake water [1]. C. violaceum and $C$. haemolyticum are closely related, phylogenetically, making them impossible to distinguish based on results of biochemical tests (i.e., the Vitek GNI + card and the API $20 \mathrm{NE}$ test). However, the lack of violet pigmentation, hemolysis of sheep blood, and positive oxidase test results allow an accurate identification. Hence, as shown in the current report, these features can be used to differentiate between these 2 bacterial species in a clinical setting.

We have investigated the minimum inhibitory concentration for C. haemolyticum. In addition, Han et al. showed differences in the antibiotic susceptibility of C. haemo lyticum and C. violaceum in clinical samples; hence, we compared them and the results are shown in Table 1 [5]. C. haemolyticum was more resistant, overall, with higher minimum inhibitory concentrations for most drugs. Thus, the ability to differentiate between these 2 bacterial species is important when infection with $C$. haemolyticum is suspected because of its greater resistance to antimicrobials, especially the $\beta$-lactams [5].

In the present report, the patient was found to have necrotizing fasciitis on day 6 based on his clinical presentation. In terms of antibiotic therapy for necrotizing fasciitis, currently acceptable regimens include the admin- 

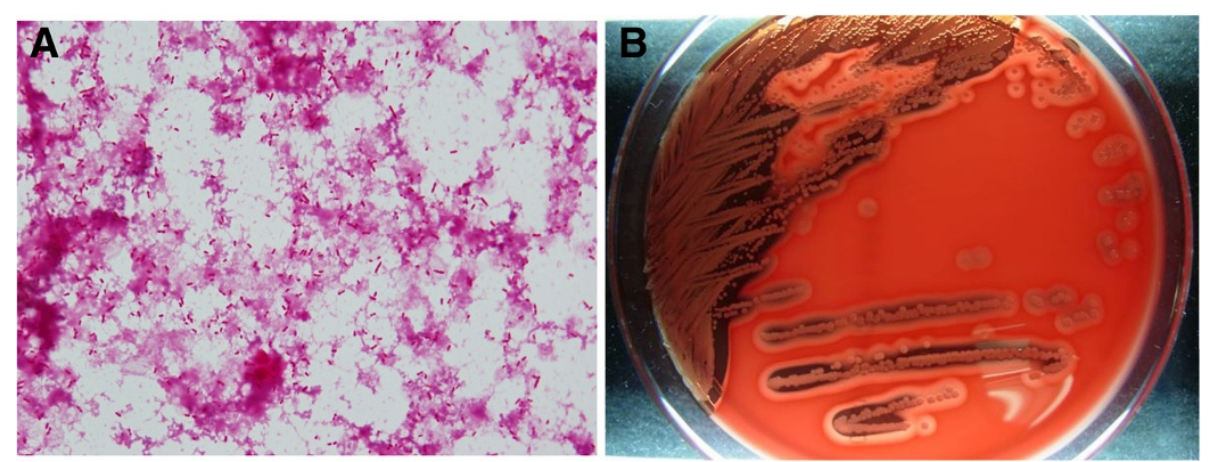

Figure 2 Microbiological results. A. A large number of short, tapered, gram-negative bacilli were present in fasciotomy. (Gram stain, $\times 400$ original magnification). B. Chromobacterium haemolyticum colonies, showing marked hemolysis on sheep blood agar after a 24-h culture.

istration of a carbapenem or $\beta$-lactam/ $\beta$-lactamase inhibitor, together with clindamycin, in addition to an agent with activity against methicillin-resistant S. aureus [6]. In addition, the Gram stain showed the bacteria to be gram-negative. Hence, without the results of the blood culture taken on day 4, we would likely have concluded that the infection was caused by Burkholderia spp., Aeromonas spp., or Pseudomonas spp. [7], and would have administrated antibiotics according to the therapy for general necrotizing fasciitis. However, C. haemolyticum

Table 1 Growth, biochemical reactions, and results of antibiotic susceptibility tests for C. haemolyticum isolates

\begin{tabular}{|c|c|c|c|}
\hline \multirow[b]{2}{*}{ Characteristic } & \multirow{2}{*}{$\begin{array}{l}\text { Present case } \\
\text { C. haemolyticum }\end{array}$} & \multicolumn{2}{|c|}{ Xan et al. [5] } \\
\hline & & C. haemolyticum & C. violaceum \\
\hline Growth on agar $\left(37^{\circ} \mathrm{C}, 5 \% \mathrm{CO}_{2}, 24 \mathrm{~h}\right)$ : & Non-pigmented & Non-pigmented & Purple \\
\hline Sheep blood & $2.3 \mathrm{~mm}, \beta$-hemolysis & $2 \mathrm{~mm}, \beta$-hemolysis & $2 \mathrm{~mm}$, no hemolysis \\
\hline Chocolate & $2.9 \mathrm{~mm}$ & $2 \mathrm{~mm}$ & $2 \mathrm{~mm}$ \\
\hline Buffered charcoal yeast extract & NA & $2 \mathrm{~mm}$, flat, dull & $2 \mathrm{~mm}$, raised, shiny \\
\hline Trypticase soy & $2.9 \mathrm{~mm}$ & $1.8 \mathrm{~mm}$ & $1 \mathrm{~mm}$ \\
\hline MacConkey & NA & $0.2 \mathrm{~mm}$, pinpoint & $1 \mathrm{~mm}$ \\
\hline Hektoen enteric & NA & No growth & $0.2 \mathrm{~mm}$, pinpoint \\
\hline Indole production (tryptophanase) & - & - & + \\
\hline Glucose fermentation & NA & $+($ weak $)$ & + \\
\hline \multicolumn{4}{|l|}{ Utilization of: } \\
\hline Mannose & - & - & + \\
\hline Mannitol & + & + & - \\
\hline Citrate & + & + & - \\
\hline Oxidase & + & + & - \\
\hline Catalase & - & $+($ weak $)$ & + \\
\hline \multicolumn{4}{|l|}{ Antimicrobial susceptibility (MIC, $\mu \mathrm{g} / \mathrm{mL})$} \\
\hline Amikacin & $>32$ & $16, S$ & 3,5 \\
\hline Cefepime & NA & $>32, R$ & 2,5 \\
\hline Ceftriaxone & NA & $>32, \mathrm{R}$ & $>32, \mathrm{R}$ \\
\hline Ciprofloxacin & $<1$ & $0.003, \mathrm{~S}$ & $0.006, \mathrm{~S}$ \\
\hline Imipenem & 2 & $6.0,5$ & $1.0, \mathrm{~S}$ \\
\hline Penicillin & NA & $>32, R$ & $>32, \mathrm{R}$ \\
\hline Piperacillin/tazobactam & NA & $>256, \mathrm{R}$ & 3,5 \\
\hline Ticarcillin/clavulanate & NA & $>256, \mathrm{R}$ & 32,1 \\
\hline Trimethoprim/sulfamethoxazole & NA & $0.094, \mathrm{~S}$ & $0.094, \mathrm{~S}$ \\
\hline
\end{tabular}


has been found to be extremely resistant to beta-lactams. Therefore, as our initial findings suggested an infection with either $C$. haemolyticum or the closely related $C$. violaceum, we provided long-term ciprofloxacin. According to a study by Aldridge et al., ciprofloxacin was the most active drug in combatting C. violaceum [8], and several studies have reported successful treatment with this therapy.

The most common symptoms of $C$. violaceum infections are fever and pain over the infected site, in association with various skin lesions [9]. To our knowledge, only 1 case of necrotizing fasciitis involving C. violaceum has been reported [10]. According to the pathology results, the patient in the current report had necrotizing fasciitis. Chattopadhyay et al. have recommended aggressive debridement for cases of C. violaceum infection [11].

\section{Conclusions}

C. haemolyticum should be considered in the differential diagnosis of skin lesions that progressively worsen after trauma involving exposure to river or lake water, even in temperate regions. Second, early blood cultures for isolation and identification are important for initiating proper antimicrobial therapy.

\section{Consent}

Written informed consent was obtained from the patient for publication of this case report and the accompanying images. A copy of the written consent is available for review by the Editor of this journal.

\section{Competing interests}

The authors declare that they have no competing interests.

\section{Authors' contributions}

$\mathrm{MO}, \mathrm{KS}, \mathrm{YO}, \mathrm{MN}, \mathrm{TI}$, and $\mathrm{AM}$ contributed to patient management. MN and CK performed the microbiological culturing and identification. $\mathrm{MO}$ and $\mathrm{RI}$ drafted the initial manuscript. YO, MN, TI, and AM contributed to writing the report. KS, SN, and NY critically reviewed the manuscript. All the authors have provided written consent for publication. All authors read and approved the final manuscript.

\section{Acknowledgement}

We would like to acknowledge Takako Sakamaki and Toshiko Ooishi for their assistance, and Katsuhiko Hashimoto, Itaru Saito, Fumihito Ito, Yoshibumi Kumada, and Hideyuki Yokoyama for their assistance with patient management.

\footnotetext{
Author details

'Department of Emergency and Critical Care Medicine, Ohta Nishinouchi Hospital, 2-5-20 Nishinouchi, 963-8558 Koriyama, Fukushima, Japan. ${ }^{2}$ Department of Emergency and Critical Care Medicine, The University of Tokyo Hospital, 7-3-1 Hongo, 113-8655 Bunkyo-ku, Tokyo, Japan. ${ }^{3}$ Department of Emergency and Critical Care Medical Center, Fukushima Medical University Hospital, 1 Hikariga-oka, 960-1295 Fukushima City, Japan. ${ }^{4}$ Department of Medicine, Ohta Nishinouchi Hospital, 2-5-20 Nishinouchi, 963-8558 Koriyama, Fukushima, Japan. ${ }^{5}$ Department of Bacteriology, Fukushima Institute of Public Health, 16-6 Mitouchi, Houkida, Fukushima city, Fukushima, Japan.
}

Received: 3 April 2013 Accepted: 28 August 2013

Published: 3 September 2013

\section{References}

1. Lima-Bittencourt Cl, Costa PS, Barbosa FA, Chartone-Souza E, Nascimento AM: Characterization of a Chromobacterium haemolyticum population from a natural tropical lake. Lett Appl Microbiol 2011, 52:642-650.

2. Soby SD, Gadagkar SR, Contreras C, Caruso FL: Chromobacterium vaccinii sp. nov. isolated from native and cultivated cranberry (Vaccinium macrocarpon Ait.) bogs and irrigation ponds. Int J Syst Evol Microbio/ 2012, 63:1840-1846.

3. Yang $\mathrm{CH}$, Li YH: Chromobacterium violaceum infection: a clinical review of an important but neglected infection. J Chin Med Assoc 2011, 74:435-441.

4. Sultan HY, Boyle AA, Sheppard N: Necrotising fasciitis. BMJ 2012, 345:e4274.

5. Han XY, Han FS, Segal J: Chromobacterium haemolyticum sp. nov., a strongly haemolytic species. Int J Syst Evol Microbiol 2008, 58:1398-1403.

6. Mandell G, Bennett J, Dolin R: Mandell, Douglas, and Bennett's Principles and Practice of Infectious Diseases, 7th Edition. Philadelphia: Churchill Livingston; 2010.

7. Campbell Jl, Lan NP, Qui PT, Dung LT, Farrar JJ, Baker S: A successful antimicrobial regime for Chromobacterium violaceum induced bacteremia. BMC Infect Dis 2013, 13:4.

8. Aldridge KE, Valainis GT, Sanders CV: Comparison of the in vitro activity of ciprofloxacin and 24 other antimicrobial agents against clinical strains of Chromobacterium violaceum. Diagn Microbiol Infect Dis 1988, 10:31-39.

9. De Siqueira IC, Dias J, Ruf H, Ramos EA, Maciel EA, Rolim A, Labur L, Vasconcelos L, Silvany C: Chromobacterium violaceum in siblings, Brazil. Emerg Infect Dis 2005, 11:1443-1445.

10. Seigel JK, Stadler ME, Lombrano JL, Almony JS, Couch ME, Belhorn TH: Chromobacterium violaceum necrotizing fasciitis: A case report and review of the literature. Ear Nose Throat J 2012, 91:479-483.

11. Chattopadhyay A, Kumar V, Bhat N, Rao P: Chromobacterium violaceum infection: A rare but frequently fatal disease. J Pediatr Surg 2002, 37:108-110

\section{doi:10.1186/1471-2334-13-406}

Cite this article as: Okada et al:: Chromobacterium haemolyticuminduced bacteremia in a healthy young man. BMC Infectious Diseases 2013 13:406.

\section{Submit your next manuscript to BioMed Central and take full advantage of:}

- Convenient online submission

- Thorough peer review

- No space constraints or color figure charges

- Immediate publication on acceptance

- Inclusion in PubMed, CAS, Scopus and Google Scholar

- Research which is freely available for redistribution 